\section{Research Article}

To Cite: Güller P, 2021. Effects of 4-Ethyl Resorcinol and 5-Methylresorcinol on Human Carbonic Anhydrase-I and Molecular Docking Study. Journal of the Institute of Science and Technology, 11(2): 1385-1392.

\title{
Effects of 4-Ethyl Resorcinol and 5-Methylresorcinol on Human Carbonic Anhydrase-I and Molecular Docking Study \\ Pınar GÜLLER ${ }^{1 *}$
}

\begin{abstract}
Carbonic Anhydrase-I (CA-I) is the most abundant CA isozyme expressed in human erythrocytes and the gastrointestinal (GI) tract. CA-I acts in promoting biocalcification. It is well known that inhibitors of carbonic anhydrase (CAIs) are widely used in the remedy of some diseases such as edema, glaucoma, idiopathic intracranial hypertension, and osteoporosis. So, in this study, it was aimed to analyze primer effects of 4ethylresorcinol and 5-methylresorcinol on hCA-I and to clarify inhibition profiles of compounds. For this purpose, firstly hCA-I was isolated from human erythrocytes by affinity chromatography. Secondly, in vitro inhibition studies were performed and interactions between compounds and enzyme were explained via molecular docking study. Both 4-ethylresorcinol and 5-methylresorcinol inhibited the enzyme competitively with $\mathrm{K}_{\mathrm{i}}$ constant of $0.81 \pm 0.23$ and $0.79 \pm 0.14 \mu \mathrm{M}$. According to molecular docking analysis estimated free energy of binding of compounds were predicted as -4.81 and $-4.51 \mathrm{kcal}^{\mathrm{mol}}{ }^{-1}$ respectively.
\end{abstract}

Keywords: Binding energy, carbonic anhydrase-1, inhibition, in vitro, molecular docking, resorcinol

${ }^{1}$ Pınar GÜLLER (Orcid ID: 0000-0001-8482-7889), Atatürk University, Faculty of Science, Department of Chemistry, Erzurum, Turkey

*Sorumlu Yazar/Corresponding Author: Pınar GÜLLER, e-mail: ptaser@atauni.edu.tr 


\section{INTRODUCTION}

Carbonic Anhydrase-I (CA-I) is one of the $\alpha$-class CA isozymes that catalyzes the reversible conversion of carbon dioxide to bicarbonate and proton. $\mathrm{CO}_{2}$, which is the result of oxidation metabolism, needs to be converted to water-soluble form in order to prevent cellular organelles and membrane from its damage (Aggarwal and McKenna, 2012; Alterio et al., 2012). CA-I is the cytosolic enzyme and is also largely expressed in human erythrocytes and the gastrointestinal (GI) tract. CA-I and CA-II are the only isoforms that are $62.3 \%$ identical and known to be present in erythrocytes (Supuran, 2008). The amount of CA-I is five times more than that of CA-II in erythrocyte cells, but its activity is half the total CA activity in these cells because it is less active (Supuran et al., 2003). Under normal physiological conditions, the hydration activity of CA-I decreases by $92 \%$. Despite its low activity, the importance of CA-I is uncertain (Maren et al., 1976; Sly and Hu, 1995; Supuran et al., 2005). It is thought that in the absence of CA-II, CA-I may compensate for possible loss of CA-II. It was reported that in patients with CA-II deficiency CA-I was expressed a higher level in red blood cells, which compensated for the absence of CA-II (Sly et al., 1983). $\mathrm{HCO}_{3}{ }^{-}$which is the product of the reaction catalyzed by CA, rapidly binds $\mathrm{Ca}$ and forms calcium carbonate. CA-I can promote arthritis calcification, arthrosis fusion, and ossification by expediting calcium carbonate accumulation (Chang et al., 2012; Zheng et al., 2012).

Besides, in the case of breast cancer, the expression of CA-I increases at a high rate in cancerous tissue and blood and this situation causes calcification of the tumor tissue and suppression of apoptosis (Zheng et al., 2015). CA-I expression and cell calcification are suppressed when AZA (Acetazolamide), which is one of the most frequently used CA inhibitors in the clinical treatment of glaucoma, was applied to cancer cells (Chang et al., 2012; Zheng et al., 2015).

Considering the role of CA-I in promoting biocalcification, the aim of our study is to search for new CA-I inhibitors and draw attention to these inhibitors for clinical use. For this purpose, inhibition effects of 4-ethylresorcinol and 5-methylresorcinol (Figure 1) were investigated on hCA-I via both in vitro and in silico methods.

Resorcinols are known as well-rounded chemicals that can be easily used by chemists in many fields from medicine to industry to benefit living things. For example, mono-alkyl substituted resorcinols show great antiseptic properties and are widely used in a variety of therapeutic and agricultural applications. 2-alkyl substituted resorcinols have been used as a basic material in the synthesis of various pharmaceutical and agricultural reagents. Besides, 4-hexylresorcinol is used in cosmetic applications as well as pharmaceutical applications (Durairaj, 2005).

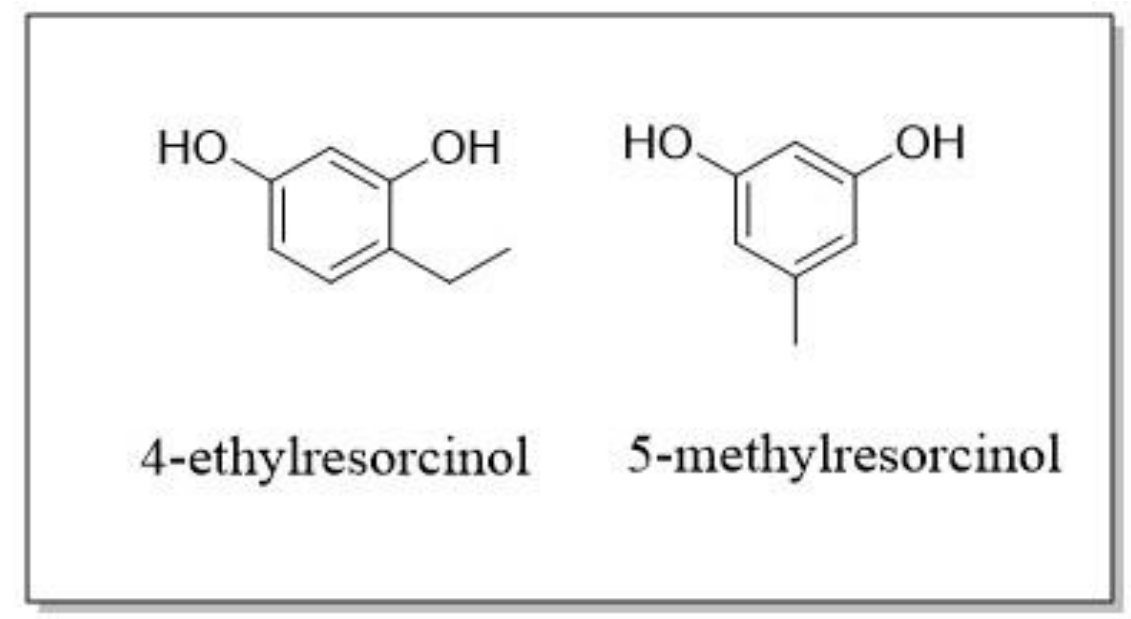

Figure 1. Structure of compounds of which inhibition mechanisms were studied on hCA-I 


\section{MATERIALS AND METHODS}

\section{Materials}

Sepharose-4B, p-nitrophenyl acetate (PNF), dialysis bag and L-tyrosine were procured from Sigma Chem. Co. and all other chemicals from E. Merck AG. 5-methylresorcinol, and 4-ethylresorcinol were obtained from Sigma and Acros. The human erythrocyte was taken from the Turkish Red Crescent Blood Centre (Erzurum Branch).

\section{Methods}

\section{Enzyme assay}

CA-I was assayed according to its esterase activity put by Verpoorte et al. (1967). The carbonic anhydrase enzyme catalyzes the hydrolysis of p-nitrophenylacetate (PNF) to p-nitrophenol or pnitrophenylate ion which gives maximum absorption at $348 \mathrm{~nm}$.

\section{Purification of hCA-I via affinity chromatography}

Erythrocytes obtained from the Erzurum Turkish Red Crescent, were hemolysis by stirring with five volume of ice water and cell membrane waste was precipitated by the centrifugation method for 15 $\min$ at $10000 \mathrm{rpm}$. Before hemolysate was loaded to the Sepharose 4B-L-tyrosine-sulfanylamide column the $\mathrm{pH}$ of it was step up to 8.7 by using Tris (Ekinci et al., 2007; Adem et al., 2019). Column was washed with $25 \mathrm{mM}$ Tris/HCl buffer ( $\mathrm{pH} 8.7$ ) including $22 \mathrm{mM} \mathrm{Na}_{2} \mathrm{SO}_{4}$ to clean other proteins adsorbed to the colon. Then CA-I was eluted with $25 \mathrm{mM} \mathrm{Na}_{2} \mathrm{HPO}_{4}$ buffer ( $\mathrm{pH}$ 6.3) containing $1 \mathrm{M}$ $\mathrm{NaCl}$. The active eluates were combined and dialyzed against the $50 \mathrm{mM}$ Tris/ $/ \mathrm{SO}_{4}$ buffer at $\mathrm{pH}$ 7.4. All experiments were carried out at $4^{\circ} \mathrm{C}$ and active enzyme solutions were stored at $-20^{\circ} \mathrm{C}$ for use in inhibition studies.

\section{Inhibition studies}

For analyzing the in vitro inhibition effects of 4-ethylresorcinol and 5-methylresorcinol on hCAI, activities of enzyme were assayed at five various concentrations of compounds. The activity determined in the inhibitor's absence was taken consider as $100 \%$ activity. Activities in the presence of inhibitor were calculated and Activity\%-[compound] graphs were plotted and the amount of inhibitor that reduced activity by $50 \%$ ( $\mathrm{IC}_{50}$ ) was calculated for the compounds from these plots. Activities were assayed at three various compound concentrations and five various substrate concentrations, then $1 / \mathrm{V}$ $1 / \mathrm{S}$ values were calculated and Lineweaver-Burk graphs were created. $\mathrm{K}_{\mathrm{i}}$ values and inhibition types were determined via these graphs (Lineweaver and Burk, 1934).

\section{Molecular docking studies}

Possible docking modes between molecules and hCA-I were studied by using the AutoDock4 (Morris et al., 2009). The crystal structures of hCA-I (PDB code: 3LXE) (Alterio et al., 2010) was used in docking calculations and its pdb file was downloaded from protein data bank (http://www.rcsb.org/pdb). To prepare the protein Autodock tool was used, water molecules and other unnecessary atoms were deleted, polar $\mathrm{H}$ atoms were added, missing atoms were checked, and Kollman charge was added. To calculate the energetic map, a grid spacing of $0.375 \AA$ was employed. Pdb files of ligands were converted from sdf file obtained by ChemDraw through Avogadro software. Number of torsion of ligand was set. Then, pdbqt files were prepared and saved by using Autodock tool. The appropriate binding positions, orientations, and conformations of ligands were determined by using the Lamarckian genetic algorithm. The results files were analyzed using Protein-Ligand Interaction Profiler (PLIP) Support Server. AZA (Acetazolamide) was used as standard inhibitor for hCA-I. 


\section{RESULTS AND DISCUSSIONS}

In respect of the reaction catalyzed by CAs, they play an important role in physiological functions such as respiration, $\mathrm{pH}$ and $\mathrm{CO}_{2}$ homeostasis, electrolyte secretion and lipogenesis (Gulcin et al., 2016; Imran et al., 2016).

Up to now, it was also reported that so many compounds such as hydroxyl and phenolic compounds, tetra-pyridine-triazole-substituted phthalocyanines, some uracil derivatives, acridine bissulfonamides, 1,3-bis-chalcone derivatives, pyrazole derivatives, 5-methyl-2,4-dihydro-3H-1,2,4triazole-3-one's aryl Schiff base derivatives, ureido benzenesulfonamides, chalcone substituted benzenesulfonamides, chalcones derivatives bearing morpholine moiety, Schiff bases of sulfa drugs, and alicilaldehyde-N-methylp-toluenesulfonylhydrazone were inhibited hCAs (Alyar and Adem, 2014; Esirden et al., 2015; Arslan et al., 2016; Salmas et al., 2016; Turkoglu et al., 2017; Alyar et al., 2018; Kursun Aktar et al., 2018; Lolak et al., 2019; Ozil et al., 2019; Turkan et al., 2019; Tutar et al., 2019; Arslan et al., 2020). Common CAIs such as acetazolamide (AAZ), celecoxib (CLX), ethoxzolamide (EZA), and methazolamide (MZA) have been reported as useful drugs in the treatment of many diseases such as glaucoma, edema, osteoporosis, idiopathic intracranial hypertension (Ahlskog et al., 2009).

In this research, inhibition effects of 4-ethylresorcinol and 5-methylresorcinol were examined on hCA-I through in vitro studies. Firstly, human erythrocytes CA-I isozyme was isolated via Sepharose4B L-tyrosine-sulphanilamide affinity chromatography. Then inhibition studies were performed, enzyme activities were assayed considering the inhibition by reference to PNF on basis of esterase activity. As summarized in Table 1, compounds inhibit enzyme at micromolar level. In vitro inhibition results were found in agreement with previous results in the study regarding the effects of indole-1,2,3triazole chalcone hybrids ( $\mathrm{K}_{\mathrm{i}}$ was found in a range of $0.18 \mu \mathrm{M}-5.5 \mu \mathrm{M}$ ) and pyrazole-3,4-dicarboxamides $\left(\mathrm{K}_{\mathrm{i}}\right.$ was found in ranging from $0.11 \mu \mathrm{M}$ to $1.66 \mu \mathrm{M}$ ) (Mert et al., 2016; Singh et al., 2020).

Table 1. In vitro inhibition results of 4-ethylresorcinol and 5-methylresorcinol on hCA-I

\begin{tabular}{lcccc}
\hline Inhibitor & $\mathbf{I C}_{\mathbf{5 0}}(\boldsymbol{\mu} \mathbf{M})$ & $\mathbf{R}^{\mathbf{2}}$ & $\mathbf{K}_{\mathbf{i}}(\boldsymbol{\mu} \mathbf{M})$ & Inhibition Type \\
\hline 4-ethylresorcinol & 1.27 & 0.900 & $0.81 \pm 0.23$ & Competitive \\
5-methylresorcinol & 1.12 & 0.955 & $0.79 \pm 0.14$ & Competitive \\
\hline
\end{tabular}

The inhibitory constant $\left(\mathrm{K}_{\mathrm{i}}\right)$ of 4-ethylresorcinol and 5-methylresorcinol were found as $0.81 \pm 0.23$ $\mu \mathrm{M}$ and $0.79 \pm 0.14 \mu \mathrm{M}$ respectively. As seen from Figure 2, it was found that both compounds inhibited the enzyme as competitively; that is, inhibitors have competed with PNF in binding to the active site of the enzyme. It was concluded that the inhibitory effects of 4-ethylresorcinol and 5-methylresorcinol were higher than calix [4] azacrown substituted sulphonamides and some cardiac drugs (Argan et al., 2020; Oguz et al., 2020).

Inhibition mechanisms of CAIs were classified as five different mechanisms (Supuran, 2016,2017). Since the inhibition type was found competitive inhibition, it was predicted from in vitro experiments that compounds inhibited hCA-I by binding to the active site such as 2-(benzylsulfonyl) benzoic acid (D'Ambrosio et al., 2015; Supuran, 2016).

To get insight the interactions between compounds and enzyme, molecular docking was also performed and summarized in Table 2. The estimated free energy of binding was calculated as -4.81, 4.51, and $-5.75 \mathrm{kcal}_{\mathrm{mol}}{ }^{-1}$ for 4-ethylresorcinol, 5-methylresorcinol and AZA respectively. 

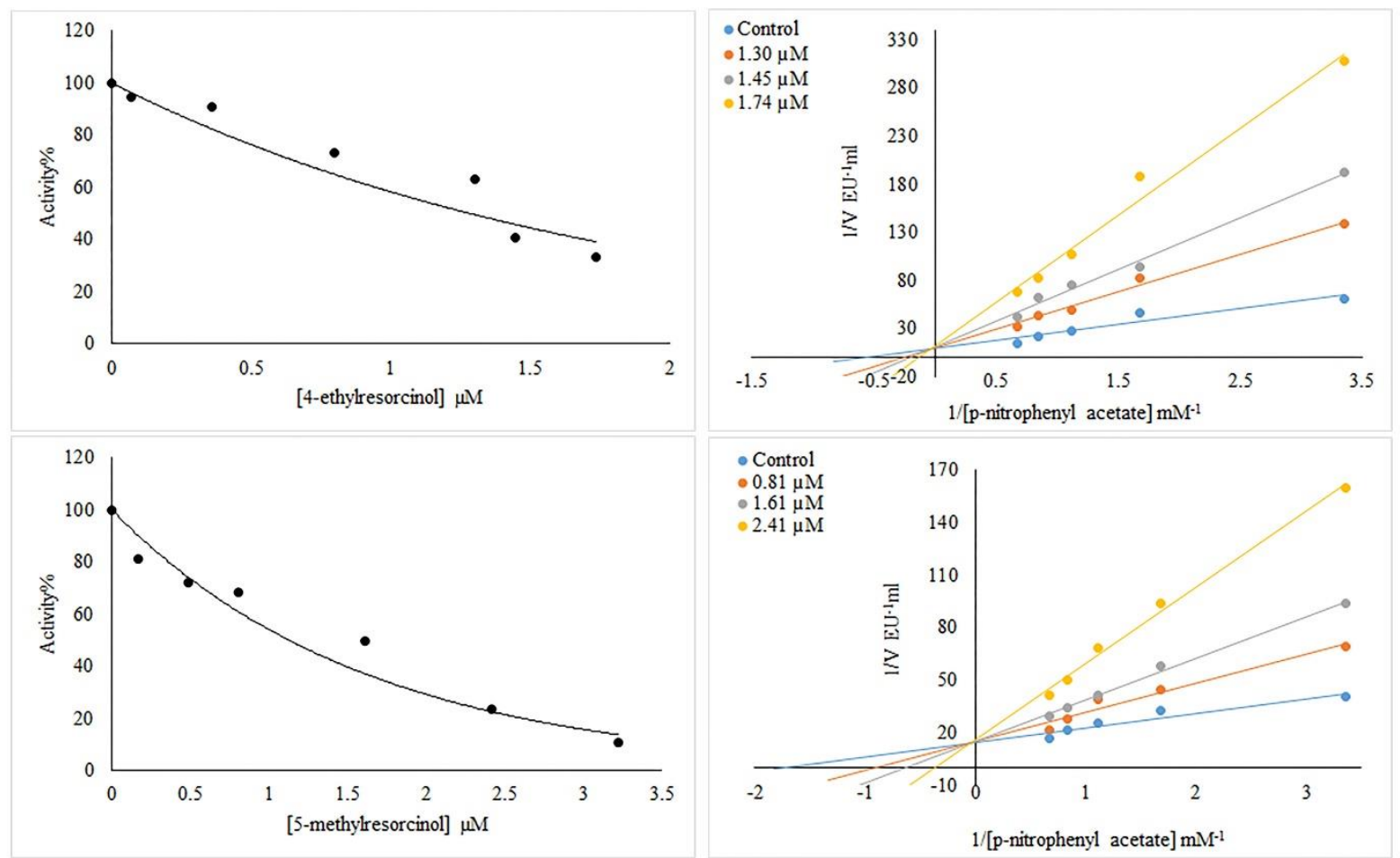

Figure 2. Activity\%-[compound] graphs and Lineweaver-Burk graphs of 4-ethylresorcinol and 5methylresorcinol

Table 2. Results of binding energies, and ligand interaction types of 4-ethylresorcinol and 5methylresorcinol with hCA-I (PDB: 3LXE)

\begin{tabular}{lccc}
\hline Ligand & $\begin{array}{c}\text { Estimated Free Energy of } \\
\text { Binding }\left(\mathbf{k c a l}^{\left.-\mathbf{m o l}^{-1}\right)}\right.\end{array}$ & H-bond & Hydrophobic Interaction \\
\hline 4-ethylresorcinol & -4.81 & Thr199, His200 & His119, Val143, Leu198, His200, Trp209 \\
\hline 5-methylresorcinol & -4.51 & Thr199, His200 & Leu198, His200 \\
\hline AZA* & -5.75 & Tyr7, His64, Thr199 & Val143, Leu198, Val207, Trp209 \\
\hline
\end{tabular}

* AZA was used as standard inhibitor for hCA-I

It was seen that AZA had three hydrogen bonds with the Tyr7, His64, Thr199 residues of enzyme and interacted hydrophobically at the residues of Val143, Leu198, Val207, Trp209. The estimated binding free energy of AZA was $-5.75 \mathrm{kcal} . \mathrm{mol}-1$, which is lower than the other two compounds. It can be concluded that its higher potency of inhibition can be due to the H-bonds. 4-ethylresorcinol showed hydrogen bonds with the Thr199 (two hydrogen bonds), and His200 (two hydrogen bonds) residues of the hCA-I on its $\mathrm{OH}$ moiety. In addition to that, the molecule exhibited several hydrophobic interactions with the His119, Val143, Leu 198, His200, and Trp209 residues (see Figure 3A). Probably due to these interactions 4-ethylresorcinol showed higher potency than 5-methylresorcinol to inhibit hCA-I. The hydrophobic interaction of 4-ethyl resorcinol is similar to that of AZA. Lowest energy conformer of 5methylresorcinol showed four hydrogen bonds at the active site of hCA-I. One of the oxygen atoms of hydroxyl moiety of the compound acted as hydrogen bond acceptor to form two H-bond with Thr199 with a distance of $3.01 \AA$ and $2.91 \AA$, respectively. The oxygen atom of other hydroxyl moiety of it acted as hydrogen bond donor against His200 with a distance of $3.83 \AA$ and $2.82 \AA$. Additionally, two hydrophobic interactions were observed between 5-methylresorcinol and the active site residues of hCAI. The interactions were displayed in Figure 3B. On the basis, it could deduce from molecular docking study that both compounds showed inhibition potency through interacting with the active pocket of hCA-I. 

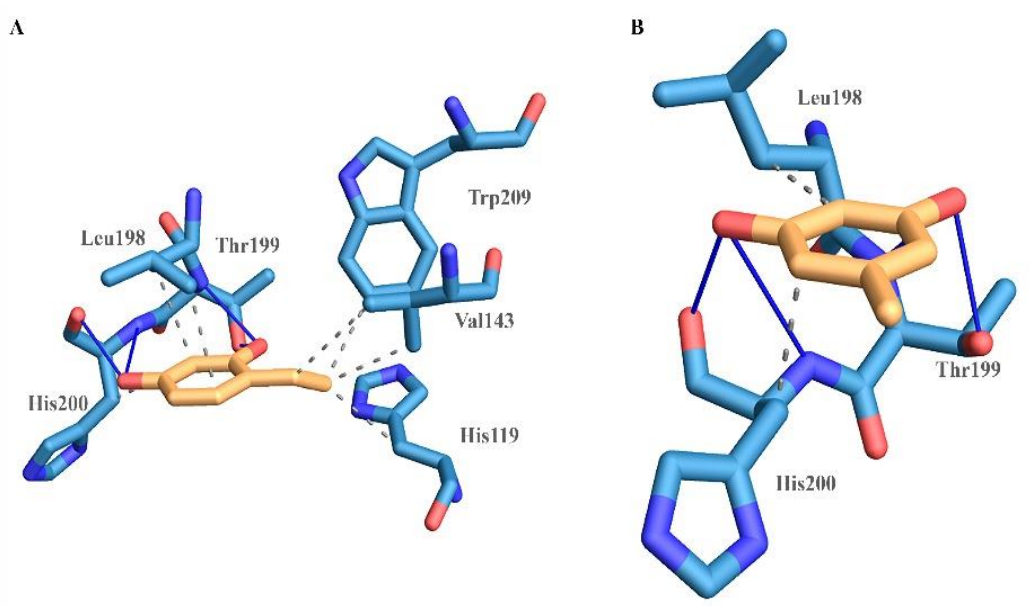

C

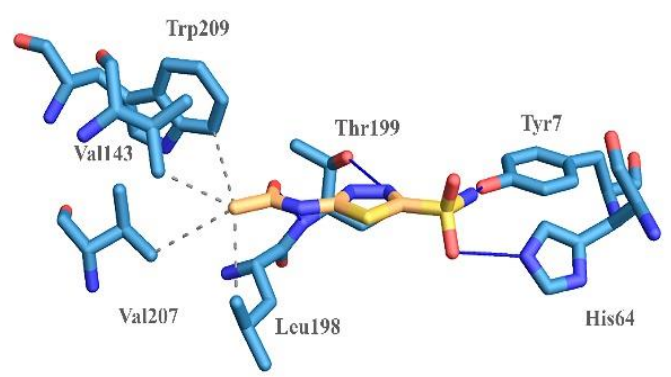

Figure 3. Potential binding modes of A) 4-ethylresorcinol, B) 5-methylresorcinol and C) AZA with hCA-1

\section{CONCLUSION}

In the present work, inhibition abilities of 4-ethylresorcinol and 5-methylresorcinol on pharmacologically significant human carbonic anhydrases hCA-I was evaluated. Both compounds showed good inhibition profiles against the enzyme and acted as competitive inhibitor. $\mathrm{K}_{\mathrm{i}}$ values were found to be $0.81 \pm 0.23 \mu \mathrm{M}$ and $0.79 \pm 0.14 \mu \mathrm{M}$ respectively. Hydrogen bonds and hydrophobic interactions were found to be dominant in inhibition mechanism of these molecules on hCA-I with estimated free energy of binding -4.81 and $-4.51 \mathrm{kcal}^{-\mathrm{mol}^{-1}}$ respectively. Moving on these, it seems that 4-ethylresorcinol and 5-methylresorcinol can give an idea on the synthesis of novel inhibitors to be used in the drug design in the case of where hCA-I's activity should be targeted.

\section{Conflict of Interest}

I declare that there is no conflict of interest during the planning, execution and writing of the article.

\section{Author's Contiibutions}

I hereby declare that the planning, execution and writing of the article was done by me as the sole author of the article.

\section{REFERENCES}

Adem S, Akkemik E, Aksit H, Guller P, Tufekci AR, Demirtas I, Ciftci M, 2019. Activation and Inhibition Effects of Some Natural Products on Human Cytosolic Cai and Caii. Medicinal Chemistry Research 28(5): 711722.

Aggarwal M, McKenna R, 2012. Update on Carbonic Anhydrase Inhibitors: A Patent Review (2008-2011). Expert Opinion on Therapeutic Patents 22(8): 903-915.

Ahlskog JKJ, Dumelin CE, Trussel S, Marlind J, Neri D, 2009. In Vivo Targeting of Tumor-Associated Carbonic Anhydrases Using Acetazolamide Derivatives. Bioorganic \& Medicinal Chemistry Letters 19(16): 48514856.

Alterio V, Di Fiore A, D'Ambrosio K, Supuran CT, De Simone G, 2012. Multiple Binding Modes of Inhibitors to Carbonic Anhydrases: How to Design Specific Drugs Targeting 15 Different Isoforms? Chemical Reviews 112(8): 4421-4468.

Alterio V, Monti SM, Truppo E, Pedone C, Supuran CT, De Simone G, 2010. The First Example of a Significant Active Site Conformational Rearrangement in a Carbonic Anhydrase-Inhibitor Adduct: The Carbonic Anhydrase I-Topiramate Complex. Organic \& Biomolecular Chemistry 8(15): 3528-3533. 
Alyar S, Adem S, 2014. Synthesis, Characterization, Antimicrobial Activity and Carbonic Anhydrase Enzyme Inhibitor Effects of Salicilaldehyde-N-Methyl P-Toluenesulfonylhydrazone and Its Palladium(Ii), Cobalt(Ii) Complexes. Spectrochimica Acta Part a-Molecular and Biomolecular Spectroscopy 131: 294302.

Alyar S, Sen CH, Alyar H, Adem S, Kalkanci A, Ozdemir UO, 2018. Synthesis, Characterization, Antimicrobial Activity, Carbonic Anhydrase Enzyme Inhibitor Effects, and Computational Studies on New Schiff Bases of Sulfa Drugs and Their Pd(Ii), Cu(Ii) Complexes. Journal of Molecular Structure 1171: 214-222.

Argan O, Cikrikci K, Baltaci A, Gencer N, 2020. The Effects of Cardiac Drugs on Human Erythrocyte Carbonic Anhydrase I and Ii Isozymes. J Enzyme Inhib Med Chem 35(1): 1359-1362.

Arslan T, Ceylan MB, Bas H, Biyiklioglu Z, Senturk M, 2020. Design, Synthesis, Characterization of Peripherally Tetra-Pyridine-Triazole-Substituted Phthalocyanines and Their Inhibitory Effects on Cholinesterases (Ache/Bche) and Carbonic Anhydrases (Hca I, Ii and Ix). Dalton Transactions 49(1): 203-209.

Arslan T, Turkoglu EA, Senturk M, Supuran CT, 2016. Synthesis and Carbonic Anhydrase Inhibitory Properties of Novel Chalcone Substituted Benzenesulfonamides. Bioorganic \& Medicinal Chemistry Letters 26(24): 5867-5870.

Chang XT, Zheng YB, Yang QR, Wang L, Pan JH, Xia YF, Yan XF, Han JX, 2012. Carbonic Anhydrase I (Ca1) Is Involved in the Process of Bone Formation and Is Susceptible to Ankylosing Spondylitis. Arthritis Research \& Therapy 14(4).

D'Ambrosio K, Carradori S, Monti SM, Buonanno M, Secci D, Vullo D, Supuran CT, De Simone G, 2015. Out of the Active Site Binding Pocket for Carbonic Anhydrase Inhibitors. Chemical Communications 51(2): 302-305.

Durairaj RB, 2005. Resorcinol : Chemistry, Technology, and Applications. Berlin ; New York, Springer.

Ekinci D, Beydemir S, Kufrevioglu OI, 2007. In Vitro Inhibitory Effects of Some Heavy Metals on Human Erythrocyte Carbonic Anhydrases. Journal of Enzyme Inhibition and Medicinal Chemistry 22(6): 745-750.

Esirden I, Ulus R, Aday B, Tanc M, Supuran CT, Kaya M, 2015. Synthesis of Novel Acridine Bis-Sulfonamides with Effective Inhibitory Activity against the Carbonic Anhydrase Isoforms I, Ii, Ix and Xii. Bioorganic \& Medicinal Chemistry 23(20): 6573-6580.

Gulcin I, Scozzafava A, Supuran CT, Akincioglu H, Koksal Z, Turkan F, Alwasel S, 2016. The Effect of Caffeic Acid Phenethyl Ester (Cape) on Metabolic Enzymes Including Acetylcholinesterase, Butyrylcholinesterase, Glutathione S-Transferase, Lactoperoxidase, and Carbonic Anhydrase Isoenzymes I, Ii, Ix, and Xii. Journal of Enzyme Inhibition and Medicinal Chemistry 31(6): 1095-1101.

Imran S, Taha M, Ismail NH, Fayyaz S, Khan KM, Choudhary MI, 2016. Synthesis of Novel Bisindolylmethanes: New Carbonic Anhydrase Ii Inhibitors, Docking, and 3d Pharmacophore Studies. Bioorganic Chemistry 68: 90-104.

Kursun Aktar BS, Oruc-Emre EE, Demirtas I, Sahin Yaglioglu A, Karakucuk Iyidogan A, Guler C, Adem S, 2018. Synthesis and Biological Evaluation of Novel Chalcones Bearing Morpholine Moiety as Antiproliferative Agents. Turkish Journal of Chemistry 42(2): 482-+.

Lineweaver H, Burk D, 1934. Th E Determination of Enzyme Dissocation Constants. Journal of the American Chemical Society 56: 658-666.

Lolak N, Akocak S, Bua S, Sanku RKK, Supuran CT, 2019. Discovery of New Ureido Benzenesulfonamides Incorporating 1,3,5-Triazine Moieties as Carbonic Anhydrase I, Ii, Ix and Xii Inhibitors. Bioorganic \& Medicinal Chemistry 27(8): 1588-1594.

Maren TH, Rayburn CS, Liddell NE, 1976. Inhibition by Anions of Human Red-Cell Carbonic Anhydrase-B Physiological and Biochemical Implications. Science 191(4226): 469-472.

Mert S, Alim Z, Isgor MM, Beydemir S, Kasimogullari R, 2016. The Synthesis of Novel Pyrazole-3,4Dicarboxamides Bearing 5-Amino-1,3,4-Thiadiazole-2-Sulfonamide Moiety with Effective Inhibitory Activity against the Isoforms of Human Cytosolic Carbonic Anhydrase I and Ii. Bioorganic Chemistry 68: 64-71.

Morris GM, Huey R, Lindstrom W, Sanner MF, Belew RK, Goodsell DS, Olson AJ, 2009. Autodock4 and Autodocktools4: Automated Docking with Selective Receptor Flexibility. Journal of Computational Chemistry 30(16): 2785-2791.

Oguz M, Kalay E, Akocak S, Nocentini A, Lolak N, Boga M, Yilmaz M, Supuran CT, 2020. Synthesis of Calix[4]Azacrown Substituted Sulphonamides with Antioxidant, Acetylcholinesterase, Butyrylcholinesterase, Tyrosinase and Carbonic Anhydrase Inhibitory Action. J Enzyme Inhib Med Chem 35(1): 1215-1223. 
Ozil M, Balaydin HT, Senturk M, 2019. Synthesis of 5-Methyl-2,4-Dihydro-3h-1,2,4-Triazole-3-One's Aryl Schiff Base Derivatives and Investigation of Carbonic Anhydrase and Cholinesterase (Ache, Buche) Inhibitory Properties. Bioorganic Chemistry 86: 705-713.

Salmas RE, Mestanoglu M, Durdagi S, Senturk M, Kaya AA, Kaya EC, 2016. Kinetic and in Silico Studies of Hydroxy-Based Inhibitors of Carbonic Anhydrase Isoforms I and Ii. Journal of Enzyme Inhibition and Medicinal Chemistry 31(1): 31-37.

Singh P, Swain B, Thacker PS, Sigalapalli DK, Purnachander Yadav P, Angeli A, Supuran CT, Arifuddin M, 2020. Synthesis and Carbonic Anhydrase Inhibition Studies of Sulfonamide Based Indole-1,2,3-Triazole Chalcone Hybrids. Bioorganic Chemistry 99: 103839.

Sly WS, Hu PY, 1995. Human Carbonic-Anhydrases and Carbonic-Anhydrase Deficiencies. Annual Review of Biochemistry 64: 375-401.

Sly WS, Whyte M, Hewettemmett D, Yu YSL, Tashian RE, 1983. Carbonic Anhydrase-Ii Deficiency Identified as the Primary Defect in the Autosomal Recessive Syndrome of Osteopetrosis with Renal Tubular-Acidosis and Cerebral Calcification. Clinical Research 31(2): A456-A456.

Supuran CT, 2008. Carbonic Anhydrases: Novel Therapeutic Applications for Inhibitors and Activators. Nature Reviews Drug Discovery 7(2): 168-181.

Supuran CT, 2016. How Many Carbonic Anhydrase Inhibition Mechanisms Exist? Journal of Enzyme Inhibition and Medicinal Chemistry 31(3): 345-360.

Supuran CT, 2017. Advances in Structure-Based Drug Discovery of Carbonic Anhydrase Inhibitors. Expert Opinion on Drug Discovery 12(1): 61-88.

Supuran CT, Scozzafava A, Casini A, 2003. Carbonic Anhydrase Inhibitors. Medicinal Research Reviews 23(2): 146-189.

Supuran CT, Scozzafava A, Conway J, 2005. Carbonic Anhydrase: Its Inhibitors and Activators, MA: Taylor and Francis.

Turkan F, Cetin A, Taslimi P, Karaman M, Gulcin I, 2019. Synthesis, Biological Evaluation and Molecular Docking of Novel Pyrazole Derivatives as Potent Carbonic Anhydrase and Acetylcholinesterase Inhibitors. Bioorganic Chemistry 86: 420-427.

Turkoglu EA, Senturk M, Supuran CT, Ekinci D, 2017. Carbonic Anhydrase Inhibitory Properties of Some Uracil Derivatives. Journal of Enzyme Inhibition and Medicinal Chemistry 32(1): 74-77.

Tutar U, Kocyigit UM, Gezegen H, 2019. Evaluation of Antimicrobial, Antibiofilm and Carbonic Anhydrase Inhibition Profiles of 1,3-Bis-Chalcone Derivatives. Journal of Biochemical and Molecular Toxicology $33(4)$.

Verpoorte JA, Mehta S, Edsall JT, 1967. Esterase Activities of Human Carbonic Anhydrases B and C. The Journal of Biological Chemistry 242: 4221-4229.

Zheng YB, Wang L, Zhang W, Xu HW, Chang XT, 2012. Transgenic Mice over-Expressing Carbonic Anhydrase I Showed Aggravated Joint Inflammation and Tissue Destruction. Bmc Musculoskeletal Disorders 13.

Zheng YB, Xu B, Zhao Y, Gu H, Li C, Wang Y, Chang XT, 2015. Ca1 Contributes to Microcalcification and Tumourigenesis in Breast Cancer. Bmc Cancer 15. 